\title{
ENGINEERING-OUT HAZARDS: DIGITISING THE MANAGEMENT OF WORKING SAFELY IN CONFINED SPACES
}

\begin{abstract}
Purpose: This paper reports upon the further development of a hybrid application programming interface (API) plug-in to Building Information Modelling (BIM) entitled 'CoSMoS'. Originally designed to engineer-out environmental hazards associated with working in a building's confined spaces (during the construction phase of a building's life-cycle), this second generation version is expanded upon to utilise archival records to proactively learn from data generated within a sensor network during the building's operations and maintenance $(\mathrm{O} \& \mathrm{M})$ phase of asset management
\end{abstract} (AM).

Research approach: An applied research methodological approach adopted utilised a two phase process. In phase one, a conceptual model was created to provide a 'blueprint map' to integrate BIM, sensor based networks and data analytics (DA) into one integral system. A literature review provided the basis for the conceptual model's further development. In phase two, the conceptual model was transposed into the prototype's development environment as a proof of concept using primary data accrued from a large educational building.

Findings: An amalgamation of BIM, historical sensor data accrued and the application of DA demonstrate that CoSMoS provides an opportunity for the facilities management (FM) team to monitor pertinent environmental conditions and human behaviour within buildings that may impact upon occupant/worker safety. Although working in confined spaces is used to demonstrate the inherent potential of CoSMoS, the system could readily be expanded to analyse sensor based network's historical data of other areas of building performance, maintenance and safety.

Originality: This novel prototype has automated safety applications for FM during the asset lifecycle and maintenance phase of a building's O\&M phase of AM. Future work is proposed in several key areas, namely: i) develop instantaneous indicators of current safety performance within a building; and ii) develop lead indicators of future safety performance of buildings.

\section{KEYWORDS}

Application Programming Interface, Building Information Modelling, Health and Safety, Confined Spaces, Facilities Management.

\section{INTRODUCTION}


"Information is the oil of the 21 st century, and analytics is the combustion engine." - Peter Sondergaard

Digitization via ubiquitous computerisation resides at the forefront of European governmental plans to augment business profitability and enhance national economic prosperity (EU, 2008; HM Gov, 2012). Amidst a plethora of innovative technological, legal and managerial developments currently shaping contemporary professional practice, the UK government's Building Information Modelling (BIM) level 2 mandate has rapidly accelerated the pace of digital transformation throughout the architecture, engineering, construction and operations (AECO) sector (HM Gov, 2012). Asset management (AM) in particular can reap many concomitant benefits associated with digitization, including: optimisation of building performance (Azhar, 2011); rapid accessibility and retrieval of asset data; streamlined maintenance management (Becerik-Gerber, et al., 2011); and efficient work order execution (Kassem, et al., 2015). These benefits have been achieved predominantly via four fundamental technologies, namely: i) networked sensors that automate data capture on building usage to generate business intelligence capital (Manyika et al., 2011, Russom, 2013; Park and Brilakis, 2016); ii) BIM that generates rich semantic and geometric data/ information for an integrated design team to collaboratively work upon throughout a building's whole life cycle (Ciribini $e t$ al., 2016; Wetzel and Thabet, 2016; Mitchell, 2017; Pärn and Edwards, 2017a); iii) big data analysis of voluminous real-time data to enable designers to optimize resultant decisions and afford greater whole lifecycle value for built assets (Ben-Alon and Sacks, 2017; Pärn et al., 2018); and iv) computational intelligence to generate systematic and deterministic prediction and/ or classification of patterns, trends and associations in design data, building performance and/ or human behaviour for improved decision making for example, failure mode diagnostics (Li et al., 2014).

When amalgamated, these aforementioned technologies have revolutionised contemporary AM practice to engender: high-speed communication; superlative cooperation between AM stakeholders (i.e. clients, asset managers and contractors); and unparalleled co-ordination of an amorphous range of operations and maintenance (O\&M) activities to enhance reliability-, availability-, maintenance- and safety-performance (Eastman et al., 2011, Pärn et al., 2017). Coalescence of technologies provide a virtuous circle of data, information and knowledge leading to organisational wisdom and commercial exploitation (Zhou et al., 2012). Of the four technologies, BIM has widely been espoused as the panacea for improved decision making 
throughout a building's whole life cycle (Rymarzak and Trojanowski, 2015; Mitchell, 2017). However, this inherent decision making ability is rarely expanded into other operational areas such as health and safety (H\&S) monitoring during a building's occupancy and use (Wetzel and Thabet, 2016).

This research builds upon an earlier prototype entitled the Confined Spaces Safety Monitoring System (CoSMoS) (c.f. Riaz et al., 2014) which produced a visualisation of confined space hazards during the construction phase of a building's life cycle using real time data. This visualisation enabled users to readily identify hazardous areas of a building. An updated version of CoSMoS presented utilises archival records to enable proactively users to learn from data generated within a sensor network during the building's O\&M phase of AM. In so doing, the research seeks to address this important knowledge gap by conceptualising a new hybrid application programming interface (API) development for monitoring H\&S hazards - namely, by integrating a BIM authoring tool (Autodesk Revit), wireless sensors (sensor motes) and data analytics (DA) into one hybrid and automated H\&S solution. This second generation version of CoSMoS demonstrates its application during building occupancy and use for safety monitoring purposes to engineer-out risks and create a building that is fundamentally safer by design. The work also neatly ties into PAS 1192 Part 6 which provides a specification for sharing structured health and safety information and is rapidly becoming the de-facto standard throughout the AECO sector (BSI, 2018). Given the huge scope of H\&S risks posed during the operational stages of an asset's lifecycle, the work specifically focuses upon the management of risks imposed upon maintenance workers operating within a building's confined spaces (purely for illustrative purposes). An associated objective seeks to provide irrefutable evidence that coalescence of technologies can automate the management of workplace risks and help mitigate the occurrence of $H \& S$ incidents.

\section{DATA AS THE NEW COMMODITY IN SAFETY MANAGEMENT}

Just as iron represented the Industrial Revolution's raw material, data constitutes the new raw material of the information age (Edwards et al., 2016). Modern building operations have become increasingly dependent upon the raw commodity of data augmented by cyber-physical connectivity achieved via: i) building automation systems (Kherbash and Mocan, 2015); ii) building management systems (BMS) (Khalid et al., 2017, Ghaffarianhoseini et al., 2017); and iii) passive infrared sensors (PIR sensors) (Joshi et al., 2017). The nexus between improving H\&S, sprawling digitalisation and the internet of things (IoT) (Ciribini et al., 2017) has 
engendered a proliferation of academic enquiry into automated H\&S monitoring and incident prevention using digital technologies (i.e. sensors, graphical simulations and visualisation in BIM). Such work has been based upon the presupposition that cyber-physical connectivity advances real-time $H \& S$ monitoring of hazardous environmental conditions that pose a serious threat to maintenance workers and building occupants (Riaz, et al., 2014). Yet hitherto, scant academic attention has been given to the development of applied-systems of digital H\&S monitoring in the post-construction (occupancy phase) of a building's life-cycle using a coalescence of technologies to improve occupational/ operational safety (ibid.).

\section{Digitalisation in the AECO Sector}

The AECO sector is plagued by H\&S incidents emanating predominantly from hazards generated by a building's design and functionality (e.g. working in confined spaces) (Rodrigues et al., 2017). Cases of advanced BIM maturity in the construction stages have demonstrated the technology's inherent aptitude to be successfully applied to H\&S planning and accident prevention (Ganah and John, 2015; Kim et al., 2016; Takim et al., 2016; Cavka et al., 2017; Fadeyi, 2017; Getuli et al., 2017). Wetzel and Thabet (2015) were amongst prominent H\&SBIM pioneers and identified five key categories of $\mathrm{H} \& \mathrm{~S}$ monitoring capabilities using: i) BIM design; ii) BIM 4D simulation; iii) rules algorithms; iv) VR based visualisation and hazard identification; and v) design for safety with BIM authoring tools. Similarly, Wetzel et al., (2017) proposed a BIM and FM integration using Asset Safety Identification Tool (ASIT) to support safety during facilities management for safety purposes albeit, this study largely ignored the palpable benefits of real-time monitoring from wireless sensor based systems.

While the management of H\&S with digital tools such as BIM per se has experienced delayed development, digitalisation of buildings has bourgeoned BIM into a de-facto preferred choice of digital tool for designers, engineers and contractors (Pärn, et al., 2017). Existing research on BIM-H\&S integration is heavily reliant upon analysing safety hazards related to the construction phase of a building's lifecycle and has hitherto ignored the possible H\&S hazards of such developments during the O\&M phase. Yet, the inherent benefits of BIM are equally applicable during building occupancy and O\&M activities. Digitalisation has promulgated new sensor based building safety monitoring techniques that have historically been applied to energy management and conservation purposes (Ciribini et al., 2017). BIM and sensor based technologies have been widely discussed in isolation for H\&S applications - for instance, BIM can enable earlier hazard analysis and prevention though design and construction stages (Zhang 
et al., 2013; Malekitabar et al., 2016; Hongling et al., 2016; Zou et al., 2017). In addition, wireless sensor based technologies have enabled the continuous and real-time monitoring of construction workers for H\&S monitoring purposes (Akinci, et al., 2006; Mohsen, 2010; Antwi-Afari et al., 2017). Consequently, the convergence of visualisation with BIM, real-time monitoring with wireless sensors, historical data accrued and DA offer a multitude of applications, although limited examples exist in practice specifically for H\&S monitoring purposes.

\section{HEALTH AND SAFETY OF CONFINED SPACES}

Surveyors, plant operators and maintenance staff in the municipal AECO sector routinely enter confined spaces to conduct regular maintenance or surveying tasks (Fishwick, 2012, Gov, 1997). Such work primarily involves manual labour intensive surveying procedures and that are virtually untouched by digitalisation (Pärn and Edwards, 2017b). Confined spaces (by virtue of their nature) are often difficult to access and egress and when conducting routine tasks, workers frequently face physical constraints such as reduced and/ or restricted mobility (IACS, 2007). These challenging working environments can pose multiple life threatening hazards for workers (Du et al., 2012; Burlet-Vienney et al., 2015b; Burlet-Vienney et al., 2015a). At present, a high number of deaths occurring each year from working in confined spaces poses a significant 'risk mitigation' challenge for industry. For example, recent statistics reveal that deaths and injury within confined spaces are a global phenomenon (c.f. Fishwick, 2012; Chinniah et al., 2017) and although the trend of fatalities has seen a slight reduction in the recent years, fatalities remain a prominent cause of concern for statutory bodies monitoring occupational hazards (Gov, 1997; Fishwick, 2012; Riaz et al., 2014; Burlet-Vienney et al., 2015a; Burlet-Vienney et al., 2015b; Chinniah et al., 2017).

\section{Risks Posed and Risk Management}

A plethora of government statutory agencies across the globe have defined and delineated the meaning of a confined space - including the Health and Safety Executive, UK; Occupational Safety and Health Administration, US; (Takim et al., 2016); Safe Work Australia, Australia; and the Institut de recherche Robert-Sauvé en santé et en sécurité du travail (IRSST), Canada. Common amongst these definitions are key characteristics pertaining to a: i) partially or fully enclosed space; ii) limited means of physical access and egress; and iii) risk of death or serious injury for workers or rescuers (HM Gov UK, 1997; Quebec Government, 2014; Government 
of Canada, 2014; Safe Work Australia, 2009). Confined spaces are not however limited to building facilities alone:

"a confined space means any place, including any chamber, tank, vat, silo, pit, trench, pipe, sewer, flue, well or other similar space in which, by virtue of its enclosed nature, there arises a reasonably foreseeable specified risk." (HM Gov UK, 1997)

Risks posed in confined spaces originate from: i) atmospheric hazards where oxygen levels are reduced to unsafe levels (HM Gov UK, 1997); ii) physiological hazards such as airborne gases, vapours and dusts, that may cause injury from fire or explosion (ibid.); and/ or iii) physical hazards such as engulfment in a confined space (NIOSH, 1994; Safe Work Australia 2009). The UK Government's Confined Spaces Regulations 1997 discusses more specified risks posed to any person at work consisting of: i) serious injury arising from a fire or explosion; ii) loss of consciousness from an increase in body temperature; iii) loss of consciousness or asphyxiation arising from gas, fume, vapour or the lack of oxygen; iv) drowning arising from an increase in the level of a liquid; and/ or v) asphyxiation arising from a free flowing solid or the inability to reach a respirable environment due to entrapment by a free flowing solid (NIOSH, 1994). Of these fatal and near fatal risks the most commonly occurring hazards are toxicity, fire and asphyxiation - all of which relate to either temperature or oxygen levels which can be monitored via sensor motes that automatically upload data into a BMS.

In instances where it is necessary to access such a space, risk management is mandated by regulatory bodies (Burlet-Vienney et al., 2015b). Risk management consists of identifying hazards, assessing risks and introducing adequate control measures to manage such (ibid.). Fishwick (2012) proffered that adequate planning of unanticipated hazards poses an unfathomable problem (i.e. unanticipated release of poisonous gases or sudden increase in temperature). To address such unanticipated hazards, UK regulations stipulate that fixed gas detectors (measuring concentration levels) and appropriate entrances/ exits (minimum diameter of $575 \mathrm{~mm}$ ) are required, among other measures (Gov, 1997). By adhering to regulatory guidance, any risks and hazards can potentially be eliminated/ minimised by identification, assessment and mitigation control measures. Albeit, compelling statistics and case studies (c.f. NIOSH, 1994; Safe Work Australia, 2009; HSE, 2013) reveal that despite progress with regulations, the AECO sector is persistently dogged by fatalities and near fatalities of workers operating in confined spaces (Fishwick, 2012). Burlet-Vienney et al., (2015b) suggest that the 
reasons underpinning prevailing H\&S incidents could be due to misinformed workers and/ or poor planning at the design stages - thus underpinning the need to learn from historical O\&M data of buildings in-use.

\section{Engineering-out the Risks (Inherently Safer by Design)}

This research posits that there are two types of engineering-out H\&S risks during a building's O\&M, namely: i) a 'physical engineered-out' solution that provides an additional layer of safety for a building in-use that mitigates human errors, acts or omissions; and ii) a 'DA engineered-out' solution that provides an invaluable opportunity for architects and designers to learn from a building's O\&M data and so influence the future design of safer buildings. To optimise occupant/ worker safety, both strategies should work in tandem. Hinze and Wiegand (1992) have long established the importance of 'data informed' design decision making and its role in the reduction of $\mathrm{H} \& S$ risks during the construction and operations phases of a building's whole life-cycle (c.f. Design for safety (DfS). The DfS concept attempts to integrate safety knowledge into the design process so that buildings are inherently safer by design (Wang and Ruxton, 1997; Gambatese, et. al., 2008). Yet, an overwhelming rate of accidents and fatalities in confined spaces challenge current codes of practice for working in confined spaces and provide anecdotal evidence that design practitioners are not particularly familiar with risks or how to produce a reliable 'data informed' assessment of these risks. Often design knowledge and technical improvements are in reaction to a previous design failure (Bluff, 2003), thus undermining designers' capacity to comprehend maintenance requirements of a 'living building' in-use (Gov, 1997). Instead, designers specify additional 'physical' safety features (e.g. incorporated manholes, redesigned need for entry, incorporated rodding eyes and nozzles for atmospheric testing) (Gov, 1997). Such negligence orchestrated by designers leaves the O\&M maintenance workers/ operators at risk of serious injury or death (Burlet-Vienney et al., 2015a).

Despite this risk, maintenance workers/ operators reside at the sharp-end of designing and implementing bespoke risk mitigate strategies when required to enter confined spaces; many of whom often struggle to adhere to the minimum requirements of governing regulations (ibid.). Due to the large proportion of existing 'pre-legislative' facilities (many of which have not incorporated adequate $\mathrm{H} \& \mathrm{~S}$ design consideration), there is a need to further reduce risks during the O\&M stage of building occupancy and use. Improved hazard analysis using DA to monitor pertinent environmental conditions and human behaviour within buildings will allow 
facility managers to augment occupant/worker safety and designers to proactively improve future building designs.

\section{SENSOR DATA ANALYTICS (DA) FOR BUILT ENVIRONMENT}

BIM within the AECO sector, provides a platform for sharing both semantic and geometric data throughout a built environment asset's lifecycle (Vanlande et al., 2008; Pärn et al., 2017). Similarly, wireless sensor network (WSN) technology has gained prominence within the management of built environmental assets post construction (Li and Becerik-Gerber, 2011). A WSN is a wireless network of sensors (also known as nodes) to provide real-time monitoring of physical or environmental conditions (such as temperature, pressure etc.) within built environment systems and can link to a BMS to maintain historical O\&M data (Cook and Das, 2004). There have been significant attempts to integrate BIM with different sensing technologies to specifically improve: environmental monitoring (Piza, et al., 2005); health and safety (H\&S) management (Shiau and Chang, 2012; Guven et al., 2012); building performance (Guinard et al., 2009; Katranuschkov et al., 2010; Attar et al., 2011; Setayeshgar et al., 2013); and optimized energy consumption (Becerik-Gerber et al., 2011). Consequently, there has been shift from model-based management of building information (i.e. BIM 1.0) to an integrated environment (i.e. BIM 2.0) of distributed up-to-date information (Underwood and Isikdag, 2011). Technologies such as WSN, cloud computing, mobile devices and application logs are the new facilitators of this paradigm shift which is capable of generating enormous amount of new, structured and unstructured real-time data often referred to as big data (Mohanty et al., 2013; IBM, 2017). Big data consists of those initiatives and processes that involve extremely large data sets that are too diverse, fast-changing and their size is beyond the ability of conventional data processing techniques (Kitchin, 2014; Wu et al., 2015).

DA is considered to be a more proactive approach towards data management than conventional business intelligence (BI) (Laursen and Thorlund, 2010) and involves gaining future insights for meaningful information and actionable decisions. DA involves: rigorous use of data, statistical and quantitative analysis, explanatory and predictive modelling (Davenport and Harris, 2007); problem solving methods such as optimization (Wang, 2014); prescriptive analytics and improved forecasting models (Gangotra and Shankar, 2016); and the use of both structured data (often stored in relational database management systems) and unstructured data (widely available through various sources such as the web and a variety of sensors) (Chen $e t$ 
$a l ., 2012)$. All of these attributes are essential for the contemporary facilities management team and building designers who seek greater knowledge of a building's safety performance in-use.

The digital transformation of the built environment has engendered new possibilities to preempt environmental and spatial hazards, for instance, with earlier hazard identification and risk assessment at the design stages (Hu and Zhang, 2011; Choi et al., 2014; Zou et al., 2017; Getuli et al., 2017; Martínez-Aires et al., 2018) or when using a confined space (Du et al., 2012; Riaz et al., 2014; Burlet-Vienney et al., 2015a). Malekitabar et al., (2016) suggest that such possibilities are realised from the inherent structuring of information through object orientated modelling (OOM) underpinning BIM. Consequently, the addition of safety related information through rich semantic information associated hierarchically to existing geometric design data could enable limitless opportunities for $H \& S$ hazards analysis that may pre-empt $H \& S$ incidents (c.f. Ding et al., 2012; Zhang et al., 2013; Wetzel and Thabet, 2015; Zhang et al., 2015; Martínez-Aires et al., 2018). The aforementioned research demonstrates that BIM and its inherent information structuring can be successfully utilised for integrating with wireless sensor data and to visualise confined spaces in a digital environment. This body of extant literature also provides motivation to extend CoSMoS throughout the built environment in order to better manage the environmental hazards/ risks posed when working in a building's confined spaces (Riaz et al., 2014). The research carried out for this purpose explored integration of BIM, WSN and DA with the objective of monitoring and 'learning' from archival environmental data collected from confined spaces.

\section{METHODOLOGY: DEVELOPING THE SECOND GENERATION CoSMOS}

The built environment is rapidly transforming with the aid of digital technologies into 'smart buildings' and 'smart cities'; where automated data accrual and concomitant decision making have become inextricably linked within the fabric of contemporary facilities management practice. In turn, this metamorphosis has progressively converted 'traditional' into 'digital economies' that are set to revolutionise global trade, industry and commerce under the guise of the fourth industrial revolution (Industry 4.0). To develop the second generation of CoSMoS, an applied methodological approach was adopted that used data accrued from an educational building; where applied research represents non-systematic inquiry that seeks to address a specific problem (Bajpai, 2011). The FM team managing this building had noted that they required greater intelligence from an extensive range of data accrued and gave permission for the research team to use such subject to: i) confidentiality of participants being preserved; and 
ii) wider dissemination of the research findings. Within this methodological framework, a two phase process was adopted. First, a conceptual model was created that sought to provide a 'blueprint map' to integrate BIM, sensor based networks and DA in one system. To achieve this development, an extensive review of extant literature was conducted, focusing upon the risks imposed upon maintenance workers operating within a building's confined spaces. Second, the conceptual model was then transposed into the prototype's development environment. A discussion of the work then follows.

\section{The Conceptual 'Blueprint' Model}

Figure 1 illustrates a digital sensory evaluation system for engineering out risks with continuous monitoring of confined spaces. A network of digital sensory technologies compare continuous on-line data gathered to benchmark reference indicators to identify hazardous peaks and troughs in a time series. Cumulatively, these technologies coalesce in one integrated system (CoSMoS) and constitute biomimicry of the human senses, namely: i) 'touching' via pertinent environmental data (such as temperature and humidity) collated through a wireless sensor network of sensor motes and aggregators. Continuous monitoring of data collected and stored will ensure that any emergent risks posed are identified thus preventing unnecessary worker/ occupant exposure to these hazards; ii) 'hearing' audible warning alarms using real-time data when the environmental parameters (i.e. temperature and humidity) values exceed benchmark indicators set. Cumulatively, automation within touching and hearing are able to engineer out hazards before they progress to a dangerous state; and iii) 'seeing' potential hazards using visualisation of environmental data acquired from sensors and BIM model. Visulaisation allows members of the facilities management team to readily identify the location of potential hazards within the building. Hazard spotting in this manner acts as an invaluable first line of defence that seeks to mitigate risks encountered before they pose a serious threat to H\&S.

\section{$<$ Insert Figure 1 about here>}

The conceptual model prototype contributes to this aforementioned transformation and is analogous to a physiological examination; where, a combination of tacit knowledge and sensory perceptions of a medical practitioner and ancillary medical equipment are utilised to develop an accurate prognosis. In a similar vein, the conceptual model combines inherent expert knowledge of hazards within confined spaces and uses tri-axial digital sensor based technologies to conduct on-board condition-based monitoring of the environment to evaluate 
fitness for human habitation. The remote condition-based monitoring of confined spaces using the conceptual model therefore, augments existing manual risk control measures and monitoring procedures implemented by mitigating risks posed to maintenance workers operating within spaces that have previously been left unmonitored and remain unsuitable for prolonged access and manual work. Importantly, this advanced technological intervention does not abdicate health and safety managers' responsibility in conducting a thorough risk assessment prior to conducting work in confined spaces. Instead, the conceptual model adds an additional layer of protection to attenuate any human acts, errors or omissions that may occur when implementing risk control mitigation strategies. Notably, this updated version expands upon a first generation of CoSMoS by utilising archival records to proactively learn from data generated within a sensor network during the building's O\&M phase of AM. Such work has significant implications in the area of soft landings (within a building delivery process) to ensure that future decisions made about similar buildings are based upon lessons learnt from an existing building's operational performance and fulfilling client requirements (Gana et al., 2018).

\section{The Development Environment}

Having created a conceptual model, a landscape survey of technologies used for environmental monitoring was then conducted. The prototype 'CoSMoS' (c.f. Riaz et al., 2014) formed the basis for a second generation proof of concept that could be implemented at the operational stages of a building for safety monitoring purposes at confined spaces (using the aforementioned 'blueprint' as a template. The prototype's development environment incorporated: Crossbow's TolesB mote (Wireless Sensors); Autodesk Revit ${ }^{\mathrm{TM}}$ Architecture 2013 (BIM Software); Visual Studio.Net (Software Development Environment); and SQL Server (Database Management System). The application ran on a Revit ${ }^{\mathrm{TM}}$ server and was programmed to: read sensor data from motes; convert raw sensor values into machine readable format; and store the collected data into a database. The self-updating BIM model in CoSMoS displayed the real-time sensor data acquired through a database link between Revit ${ }^{\mathrm{TM}}$ external application and a database system. Therefore, the CoSMoS application not only dealt with centralized sensor data storage but also included BIM integration where the BIM platform was used as a visualization tool.

A data driven approach developed integrates BIM with WSN in order to pre-empt changes in oxygen and temperature readings beyond the threshold levels. Therefore, the problem is multidimensional in nature and involves creating an accurate representation of the system's elements 
and then using this representation to help improve the occupant's health and safety. For this purpose, two pairs of temperature and oxygen sensing motes are placed in two different locations, designated as confined spaces of a facility by the building's estates management department as part of their risk management approach (see Figure 2 - Areas ID35 and ID56). Area ID35 represents a space above a lecture theatre to accommodate service and air conditioning ducts. Periodically, these ducts require access and egress therefore, this area contains multiple confined space hazards. Similarly, Area ID56 represents a small space above a doorway that provides access and egress to service and air conditioning ducts. Both areas are highlighted in 'red' to make them readily identifiable. Note that this example reported upon here is for confined spaces but that other hazards could have been used as exemplars of the systems use and functionality.

For the proof of concept's development environment, a three stage were undertaken, namely: i) set up of sensors; ii) data retrieval stage; and iii) API visualisation.

<Insert Figure 2 about here>

i) Setting up of sensors - Aggregator motes are programmed to aggregate the sensor values received from other sensing motes and forward them along with its own sensed value to a serial port. Aggregator motes are connected to a BIM server using a standard Universal Serial Bus (USB) interface. CoSMoS deals with a continuous stream of timestamped sensor data and from multiple types of motes (temperature and oxygen in case of prototype system) and is thus capable of producing a large volume and variety of data. Using this large dataset, the analytics collate data and information that enable members of the facilities management team to 'learn' about the environment of the confined spaces by measuring, monitoring and interpreting the collated data through pattern recognition and outlier detection.

ii) Data retrieval stage - For DA purposes, the application retrieves historic data in a Comma Separated Values (CSV) file format which consists of stored 'Sensor Value' along with 'SensorID', 'Sensor type', 'Room ID' and 'Timestamp' in Comma Separated Values (CSV) file format. The dataset was analysed for insights using R Studio, a free and open-source integrated development environment for the $\mathrm{R}$ programming language. The $\mathrm{R}$ programming language was chosen because it is: $\mathrm{i}$ ) 
freeware that allows to adaptation without incurring cost expenditure; and ii) a popular platform for statistical computing and graphics (RStudio, 2018). The package used for graphics was ggplot2 that allows for complex and sophisticated visualizations of multidimensional data. Emphasis here focused upon producing use-friendly graphics that could be read and interpreted by non-academic members of a facilities management team.

iii) API visualisation - the CoSMoS application was extended to import these visualizations for data insights and outlier detection. The first generation CoSMoS focused on real time data and used BIM as a visualisation tool on construction sites. The second generation CoSMoS application, on the other hand, is expanded upon to utilise historic sensor data collected over the building lifetime to proactively understand the building's operations and maintenance. Figure 3 demonstrates the API development through a coalescence of big data, BIM and sensor motes have engendered the CoSMoS prototype specifically designed for the monitoring prevailing environmental parameters within confined spaces for asset managers.

<Insert Figure 3 about here>

\section{AUTOMATING THE MEASUREMENT OF ENVIRONMENTAL ATTRIBUTES}

The data-sensing layer consists of a network of wireless sensing motes that measure the environmental attributes, temperature and oxygen in this case, of a physical building. Once deployed in a facility, motes will initialize and implement operations such as neighbour discovery, data sensing, sensor data processing and sensor data transmissions. Motes are programmed to aggregate the sensor values coming from other sensing motes and forward them along with its own data to sensing gateway mote. A gateway mote is connected to a server using a standard Universal Serial Bus (USB) interface. The back-end sensor application runs on a Revit Server to read sensing gateway mote. Sensor application is programmed to: read TelosB gateway mote; convert acquired raw sensor values in a machine/human understandable format; and push the data to data storage layer. To generate the sensor value pattern over a given period of time, current as well as historic sensor data is retrieved and data visualizations are generated using ggplot2 package in RStudio. The application then projects these visualizations in the plugin upon users request (see Figures 4 and 5) (cf. Dibley et al., 2012). 
Figure 4 represents plots of oxygen and temperature levels for three months starting from November 2016. The visualization also presents extreme values that were achieved by applying specific conditions in order to check the sensitivity of the setup, for example, on the $17^{\text {th }}$ November the temperature reading recorded $50.8{ }^{\circ} \mathrm{C}$ which was achieved by lighting a controlled fire in the specific room. The purpose was to observe how the changes in temperature and oxygen levels are recorded and represented through the CoSMoS plugin. Similarly, the oxygen levels were observed across the study period.

Another useful representation is to detect outliers (see Figure 5). Outlier detection becomes important in this context because properties of the system at that specific point impact upon environmental conditions e.g., the number of occupants in the room at that particular time and day etc. DA integration makes it possible to easily identify and visualize outliers in the data using for example, univariate analysis. Boxplots for all the three months are generated for comparison. On weekday 3, the oxygen levels were much higher because of the presence of extreme outliers - reasons for this peak are currently being investigated. The user interface readily allows for user changes so that alternative visualizations can be generated to examine other environmental patterns and factors. For example, historical data can be used to compare oxygen and temperature levels across all seasons and multiple numbers of years. Visualization of sensory data is one of the main advantages of integrating DA into CoSMoS.

\section{Further Development}

The results illustrated are for a relatively small time period ( 3 months). However, there are a number of other approaches that can further improve the applicability of the prototype, provided sufficient data is gathered. There are three key areas of further development. First, is to apply machine learning algorithms to data collected on existing buildings designed and operated. The goal for machine learning is to develop self-learning and self-improving algorithms that can be used for automating predictions for members of the FM team. For CoSMoS, a reinforcement learning agent (Sutton and Barto, 1998), starting from no prior information about the oxygen and temperature levels or the climate system, will learn individual representations for these variables. These representations are further analysed to plan for its future course of action optimizing the specified reward function. In doing so, the 
algorithm continues refining its representations leading to improvement in performance. This offers immense opportunities for improving H\&S within a built environment.

Second, is to apply lessons learnt from existing buildings to influence future design practice and thus extend the use/application of soft landings. Currently, architects and designers rarely study the performance of a building designed and constructed once handed over to the client and/or act upon occupant feedback (collected via post occupancy evaluations conducted) (cf. Pärn et al., 2017). Hence, a significant opportunity to learn from a building's design is lost and mistakes made are often replicated in other future building design developments.

Third, is to transform contemporary practice using technological innovations and accompanying further and/or higher education for FM managers and workers. The rapid pace of future development is aligned to an amalgamation of factors that have converged simultaneously, including: an exponential growth rate of digital technological development; miniaturisation and mass-manufacture of electronic componentry; and a distinct reduction in technology costs - making digital innovations far more affordable and accessible to industry and commerce. In turn, such developments engender the need for continuous up-skilling of the workforce who must optimise their usage of such innovations. This pace of technological growth is set to continue but moreover, technologies will also coalesce to provide hybrid solutions that not only encapsulate a single building but also smart cities and entire economies. Hence, opportunities for CoSMoS to expand further are significant and subject to further research investigation.

\section{CONCLUSIONS}

Digitisation achieved through advanced computerisation has engendered the fourth industrial revolution (Industry 4.0) which is set to continue unabated. Such technological development will transform the digital built environment by creating a vast and ever expanding web of cyberphysical connectivity supported by an abundance of networked senor devices that generate rich real time data and information that is recorded in databases. Retrieval and subsequent automated analysis of this data will enable operators to learn from patterns and trends in a building O\&M. Such information should be used to inform future design developments and augment the environmental, safety and financial performance of the digital built environment. The work will also provide an opportunity for all building stakeholders to improve prevailing soft landings practices and procedures by learning from an existing building's performance. 
The hybrid 'second generation' API plug-in to BIM entitled 'CoSMoS' presented in this paper focused upon safety performance and illustrates how technology can assist to learn from historical data trends as a first step towards engineering-out hazards associated with working in confined spaces. However, this approach could equally be applied to other environmental conditions within a workplace that may prove hazardous (such as the control of substances hazardous to health e.g. volatile organic compounds found in paints or cleaning fluids). This novel 'second generation' prototype offers several beneficial applications for facilities management (FM) during the asset lifecycle and maintenance phase of building O\&M. First, it provides an unobtrusive addition layer of safety that is specifically designed to mitigate human acts, errors or omissions; and second, the real time data acquisition from sensor motes, provides rich data visualizations for facility managers to optimise decision support regarding safe work practices within a confined space. Such innovation provides new insight on the palpable benefits to be derived from a coalescence of digital technologies but also serves to stimulate further intellectual and pragmatic discussion on managing asset maintenance activities through a philosophical stance of inherently safer by design.

Despite the considerable $\mathrm{H} \& \mathrm{~S}$ gains to be accrued from using CoSMoS, future research is needed to: i) develop instantaneous indicators of current safety performance within a building - harvesting environmental data of a building in-use and 3D model design data to better understand the immediate patterns of working within confined spaces and/ or other areas of a building that pose H\&S hazards. Such work will also further develop and enhance the performance of the API plug-in; and ii) develop lead indicators of future safety performance of buildings to be designed and constructed - harnessing data, information and knowledge acquired from human activity within building's in-use will enable designers to develop future building designs that 'engineer-out risks' thus making buildings inherently safer by design. 


\section{REFERENCES}

Akinci, B. Boukamp F., Gordon C. , Huber D., Lyons C. and Park K. (2006) A Formalism for Utilization of Sensor Systems and Integrated Project Models for Active Construction Quality Control. Automation in Construction, Vol. 15, No. March 2006, pp.124-138, DOI: https://doi.org/10.1016/j.autcon.2005.01.008

Antwi-Afari, M. F., Li, H., Edwards, D. J., Pärn, E. A., Seo, J. and Wong, A. Y. L. (2017). Biomechanical Analysis of Risk Factors for Work-related Musculoskeletal Disorders During Repetitive Lifting Task in Construction Workers. Automation in Construction, Vol.83, pp. 41-47. DOI: https://doi.org/10.1016/j.autcon.2017.07.007

Attar R., Hailemariam E., Breslav S., Khan A., and Kurtenbach G. (2011) Sensor-enabled Cubicles for Occupant-centric Capture of Building Performance Data. ASHRAE Annual Conference pp $1-8 . \quad$ Available via: http://www.autodeskresearch.org/pdf/6774_Final.pdf [Accessed: January, 2018].

Azhar, S. (2011) Building Information Modeling (BIM): Trends, Benefits, Risks, and Challenges for the AEC Industry, Leadership and Management in Engineering, Vol. 11, No. 3, pp. 241-252. DOI: http://dx.doi.org/10.1061/(ASCE)LM.1943$\underline{5630.0000127}$

Bajpai, N. (2011) Business Research Methods, Pearson Education India.

Becerik-Gerber, B., Jazizadeh, F., Li, N. and Calis, G. (2011) Application Areas and Data Requirements for BIM-enabled Facilities Management, Journal of Construction Engineering and Management, Vol. 138, No. 3, pp. 431-442. DOI: http://dx.doi.org/10.1061/(ASCE)CO.1943-7862.0000433

Becerik-Gerber, B., Jazizadeh, F., Li, N. and Calis, G. (2011) Application Areas and Data Requirements for BIM-enabled Facilities Management. Journal of Construction Engineering and Management, Vol. 138, No. 3, pp. 431-442. DOI: https://doi.org/10.1061/(ASCE)CO.1943-7862.0000433

Bluff, L. (2003). Regulating Safe Design and Planning of Construction Works: A Review of Strategies for Regulating OHS in the Design and Planning of Buildings, Structures and Other Construction Projects. (Working Paper 19). The Australian National University, Canberra. Available via: https://openresearchrepository.anu.edu.au/bitstream/1885/41229/3/CDM.WP19.pdf [Accessed: January, 2018].

BSI (2018) Specification for Collaborative Sharing and Use of Structured Health and Safety Information Using BIM, British Standards Institute, London. 
Burlet-Vienney, D., Chinniah, Y., Bahloul, A. and Roberge, B. (2015a) Design and Application of a 5 Step Risk Assessment Tool for Confined Space Entries. Safety Science, Vol. 80, No. December 2015, pp. 144-155. DOI: https://doi.org/10.1016/j.ssci.2015.07.022

Burlet-Vienney, D., Chinniah, Y., Bahloul, A. and Roberge, B. (2015b) Occupational Safety During Interventions in Confined Spaces. Safety Science, Vol.79, No. November 2015, pp.19-28. DOI: https://doi.org/10.1016/j.ssci.2015.05.003

Cavka, H. B., Staub-French, S. and Poirier, E. A. (2017) Developing Owner Information Requirements for BIM-enabled Project Delivery and Asset Management. Automation in Construction, Vol. 83, No. November 2017, pp. 169-183. DOI: https://doi.org/10.1016/j.autcon.2017.08.006

Chen, H., Chiang, R. H. and Storey, V. C. (2012) Business Intelligence and Analytics: from Big Data to Big Impact. MIS Quarterly, Vol. 36, No. 4, pp. 1165-1188.

Chinniah, Y., Bahloul, A., Burlet-Vienney, D. and Roberge, B. (2017) Development of a Confined Space Risk Analysis and Work Categorization Tool. Studies and Research Projects. The Institut de recherche Robert-Sauvé en santé et en sécurité du travail Available via: http://www.irsst.qc.ca/media/documents/PubIRSST/R-955.pdf [Accessed: January, 2018].

Choi, J., Choi, J. and Kim, I. (2014). Development of BIM-based Evacuation Regulation Checking System for High-rise and Complex Buildings. Automation in Construction, Vo. 46, No. October 2014, pp.38-49. DOI: https://doi.org/10.1016/j.autcon.2013.12.005

Ciribini, A. L. C., Pasini, D., Tagliabue, L. C., Manfren, M., Daniotti, B., Rinaldi, S. and De Angelis, E. (2017) Tracking Users' Behaviors Through Real-time Information in BIMs: Workflow for Interconnection in the Brescia Smart Campus Demonstrator. Procedia Engineering, Vol. $\quad$ 180, pp. 1484-1494. DOI: https://doi.org/10.1016/j.proeng.2017.04.311

Cook, D. and Das, S. (2004) Smart Environments: Technology, Protocols and Applications, London: John Wiley \& Sons.

Davenport, T. and Harris, J. (2007) Competing on Analytics. Boston: Harvard Business School Publishing Corporation.

Dibley, M., Li, H., Rezgui, Y. and Miles, J. (2012) An Ontology Framework for Intelligent Sensor-based Building Monitoring. Automation in Construction, Vol. 28, pp. 1-14. DOI: https://doi.org/10.1016/j.autcon.2012.05.018 
Ding, L. Y., Zhou, Y., Luo, H. B. and Wu, X. G. (2012) Using nD Technology to Develop an Integrated Construction Management System for City Rail Transit Construction. Automation in Construction, Vol. 21, No. January 2012, pp. 64-73 DOI: https://doi.org/10.1016/j.autcon.2011.05.013

Du, Y., Zhou, Y., Li, Y., Zhou, D., Zhang, P. and Wang, P. (2012). Experimental Simulation on Oil Gas Spreading in the Complex Confined Spaces. Procedia Engineering, Vol. 45, pp. 360-365. DOI: https://doi.org/10.1016/j.proeng.2012.08.171

Eastman, C. M., Eastman, C., Teicholz, P. and Sacks, R. (2011) BIM Handbook: A Guide to Building Information Modeling for Owners, Managers, Designers, Engineers and Contractors, London: John Wiley \& Sons.

Edwards, D.J., Pärn, E.A., Love, P.E.D. and El-Gohary, H. (2016) Machines, Manumission and Economic Machinations, Journal of Business Research, Vol. 70 pp. 391-394. DOI: http://dx.doi.org/10.1016/j.jbusres.2016.08.012

Fadeyi, M., O. (2017) The Role of Building Information Modeling (BIM) in Delivering the Sustainable Building Value. International Journal of Sustainable Built Environment, Vol. 6, No. 2, pp. 711-722. DOI: https://doi.org/10.1016/j.ijsbe.2017.08.003

Fishwick, T. (2012) Recurring Accidents: Confined Spaces. The Chemical Engineer. Available via:

https://www.icheme.org/sitecore/shell/Controls/Rich\%20Text\%20Editor/ /media/Doc uments/TCE/lessons-learned-pdfs/854fishwick.pdf [Accessed: March, 2018].

Gambatese, J., A., Behm, M. and Rajendran, S. (2008) Design's Role in Construction Accident Causality and Prevention: Perspectives from an Expert Panel. Safety Science., Vol. 46, No. 4, pp. 675-691. DOI: https://doi.org/10.1016/j.ssci.2007.06.010

Gana, V., Giridharan, R. and Watkins, R. (2018) Application of Soft Landings in the Design Management Process of a Non-residential Building, Architectural Engineering and Design Management, Vol. 14, No. 3, pp. 178-193. DOI: $10.1080 / 17452007.2017 .1324400$

Ganah, A. and John, G. A. (2015) Integrating Building Information Modeling and Health and Safety for Onsite Construction. Safe Health Work, Vol. 6, No.1, pp. 39-45. DOI: https://doi.org/10.1016/j.shaw.2014.10.002

Gangotra, A. and Shankar, R. (2016) Strategies in Managing Risks in the Adoption of Business Analytics Practices. Journal of Enterprise Information Management,Vol. 29, No. 3, pp. 374-399.DOI: https://doi.org/10.1108/JEIM-10-2014-0096 
Getuli, V., Ventura, S. M., Capone, P. and Ciribini, A. L. C. (2017) BIM-based Code Checking for Construction Health and Safety. Procedia Engineering, Vol.196, pp.454-461. DOI: https://doi.org/10.1016/j.proeng.2017.07.224

Ghaffarianhoseini, A., Zhang, T., Nwadigo, O., Ghaffarianhoseini, A., Naismith, N., Tookey, J. and Raahemifar, K. (2017) Application of nD BIM Integrated Knowledge-based Building Management System (BIM-IKBMS) for Inspecting Post-construction Energy Efficiency. Renewable and Sustainable Energy Reviews, Vol.72, No. May 2017, pp. 935-949. DOI: https://doi.org/10.1016/j.rser.2016.12.061

Gov, H. (1997) Health and Safety the Confined Spaces Regulations (1997). In: OFFICE, U. G. H. (ed.) No. 1713. Approved Code of Practice: Regulations and Guidance L101 HSE Books.

Guinard A., McGibney A. and Pesch D. (2009) A Wireless Sensor Network Design Tool to Support Building Energy Management. 1st ACM Workshop on Embedded Sensing Systems for Energy-Efficiency in Buildings, pp. 25-30. Available via: https://dl.acm.org/citation.cfm?id=1810286 [Accessed: March, 2018].

Guven G., Ergen E., Erberik M., Kurc O. and Birgönül M. (2012) Providing Guidance for Evacuation During an Emergency Based on a Real-time Damage and Vulnerability Assessment of Facilities, Computing in Civil Engineering pp. 586-593. Available via: https://www.e-education.psu.edu/geog588/sites/www.eeducation.psu.edu.geog588/files/file/Guven_etal_2012.pdf [Accessed: January, 2018].

Health and Safety Executive, (2013) Safe Work in Confined Spaces. Available via: http://www. hse.gov.uk/pubns/indg258.pdf [Accessed: January, 2018].

Hu, Z. and Zhang, J. (2011) BIM- and 4D-based Integrated Solution of Analysis and Management for Conflicts and Structural Safety Problems during Construction: 2. Development and Site Trials. Automation in Construction, Vol. 20, pp. 167-180. DOI: https://doi.org/10.1016/j.autcon.2010.09.013

Hinze, J. and Wiegand F. (1992) Role of Designers in Construction Worker Safety, Journal of Construction, Engineering and Management, Vol. 118 , No. 1992, pp. 677-684, DOI: https://doi.org/10.1061/(ASCE)0733-9364(1992) 118:4(677)

Hongling, G., Yantao, Y., Weisheng, Z. and Yan, L. (2016) BIM and Safety Rules Based Automated Identification of Unsafe Design Factors in Construction. Procedia Engineering, Vol. 164, pp. 467-472. DOI: https://doi.org/10.1016/j.proeng.2016.11.646 
IBM (2017) What is Big Data? Available via: https://www.ibm.com/big-data/us/en/ [Accessed: January, 2018].

Joshi, S. S., Eklahare, N. and Sonwane, P. (2017) WSN Based Power Management for Intelligent Building. IEEE/ASME Transactions on Mechatronics, Vol. 20, No. 2. DOI: https://doi.org/10.1109/TMECH.2014.2301716

Kassem, M., Kelly, G., Dawood, N., Serginson, M. and Lockley, S. (2015) BIM in Facilities Management Applications: A Case Study of a Large University Complex, Built Environment Project and Asset Management, Vol. 5, No. 3, pp. 261-277. DOI: http://dx.doi.org/10.1108/BEPAM-02-2014-0011

Katranuschkov P., Weise M., Windisch R., Fuchs S. and Scherer R. J. (2010) BIM-based Generation of Multi-model Views, Available via: http://www.hesmos.eu/plaintext/downloads/paper_114_final.pdf [Accessed: March 3, 2016].

Khalid, M. U., Bashir, M. K. and Newport, D. (2017) Development of a Building Information Modelling (BIM)-based Real-time Data Integration System using a Building Management System (BMS). Building Information Modelling, Building Performance, Design and Smart Construction. London: Springer. DOI: https://doi.org/10.1007/9783-319-50346-2 7

Kherbash, O. and Mocan, M. L. (2015) A Review of Logistics and Transport Sector as a Factor of Globalization. Procedia Economics and Finance, Vol. 27, pp. 42-47. DOI: https://doi.org/10.1016/S2212-5671(15)00969-7

Kim, K., Cho, Y. and Zhang, S. (2016) Integrating Work Sequences and Temporary Structures into Safety Planning: Automated Scaffolding-related Safety Hazard Identification and Prevention in BIM. Automation in Construction, Vol.70, No. October 2016, pp.128142. DOI: https://doi.org/10.1016/j.autcon.2016.06.012

Kitchin, R. (2014) The Real-time City? Big Data and Smart Urbanism. GeoJournal Vol.79, No.

1, pp. 1-14. DOI: https://link.springer.com/article/10.1007/s10708-013-9516-8

Laursen, G. and Thorlund, J. (2010) Business Analytics for Managers: Taking Business Intelligence Beyond Reporting. Hoboken, New Jersey: John Wiley \& Sons.

Li, N. and Becerik-Gerber, B. (2011) Performance-based Evaluation of RFID-based Indoor Location Sensing Solutions for the Built Environment. Advanced Engineering Informatics. Vol 25, Issue 3, pp. 535-546. DOI: https://doi.org/10.1016/j.aei.2011.02.004 
Malekitabar, H., Ardeshir, A., Sebt, M. H. and Stouffs, R. (2016) Construction Safety Risk Drivers: A BIM Approach. Safety Science, Vol. 82, pp. 445-455. DOI: https://doi.org/10.1016/j.ssci.2015.11.002

Martínez-Aires, M. D., López-Alonso, M. and Martínez-Rojas, M. (2018) Building Information Modeling and Safety Management: A Systematic Review. Safety Science, Vol. 101, pp.11-18. DOI: https://doi.org/10.1016/j.ssci.2017.08.015

Mitchell, T. L. (2017) The Future of FM: Integrating Asset Management Planning Practices to Lead Transformation Change. Corporate Real Estate Journal, Vol. 6, No. 4, pp. 349357.

Mohanty, Soumendra, M. Jagadeesh and H. Srivatsa, (2013) Big Data Imperatives: Enterprise 'Big Data' Warehouse, 'BI’ Implementations and Analytics, Apress, 2013, ISBN 978$1-4302-4873-6$

Mohsen S. S., Saiedeh N.R., Lucio S., Mario B., Carlos H.C., Ioannis B., Jochen T., Patricio A.V., Carl H., James G., Burcu A. and Zhenhua Z., (2010) CEC: Data Fusion Approaches and Applications for Construction Engineering, Journal of Construction Engineering and Management Vol. 1, No. 1, pp.196.

Pärn, E. A., Edwards, D. J. and Sing, M. C. P. (2017) The Building Information Modelling Trajectory in Facilities Management: A Review. Automation in Construction, Vol. 75, pp.45-55. DOI: https://doi.org/10.1016/j.autcon.2016.12.003

Pärn, E.A. and Edwards, D.J. (2017a) Conceptualizing the FINDD Toolkit: A Case Study of BIM/ FM Integration, Automation in Construction, Vol. 80, pp. 11-21. DOI: http://dx.doi.org/10.1016/j.autcon.2017.03.015

Pärn, E.A. and Edwards, D.J. (2017b) Vision and Advocacy of Optoelectronic Technology Developments in the AECO Sector: A Review, Built Environment Project and Asset Management, DOI: https://doi.org/10.1108/BEPAM-11-2016-0081

Pärn, E.A., Edwards, D.J. and Sing, M.C.P. (2018) The Origins and Probabilities of MEP and Structural Design Clashes within a Federated BIM, Automation in Construction, Vol. 85, pp. 209-219. DOI: https://doi.org/10.1016/j.autcon.2017.09.010

Piza H.I., Ramos F.F. and Zuniga F. (2005) Virtual Sensors for Dynamic Virtual Environments. 1st IEEE Int. Workshop on Computational Advances in Multi-Sensor Adaptive Processing, pp. 177-180.

Riaz, Z., Arslan, M., Kiani, A. K. and Azhar, S. (2014) CoSMoS: A BIM and Wireless Sensor Based Integrated Solution for Worker Safety in Confined Spaces. Automation in Construction, Vol. 45, pp. 96-106. DOI: https://doi.org/10.1016/j.autcon.2014.05.010 
Rodrigues, F., Barbosa, A. and Baptista, J. S. (2017) Hazards Identification During Design Phase. Occupational Safety and Hygiene V: Proceedings of the International Symposium on Occupational Safety and Hygiene (SHO 2017), April 10-11, 2017, Guimarães, Portugal, 2017. CRC Press, 415.

RStudio (2018) RStudio RStudio IDE Features. Available via: https://www.rstudio.com/products/rstudio/features/ [Accessed: November 2017]

Rymarzak, M. and Trojanowski, D. (2015) Asset Management Determinants of Polish Universities. Journal of Corporate Real Estate, Vol. 17, No. 3, pp. 178-197. DOI: https://doi.org/10.1108/JCRE-02-2015-0006

Setayeshgar S., Hammad A., Vahdatikhaki F., and Zhang C. (2013) Real Time Safety Risk Analysis of Construction Projects using BIM and RTLS, Available via: http://www.iaarc.org/publications/fulltext/isarc2013Paper224.pdf

[Accessed:

December, 2017].

Shiau Y. C. and Chang C. T. (2012) Establishment of Fire Control Management System in Building Information Modelling Environment, Available via: http://onlinepresent.org/proceedings/vol5_2012/11.pdf [Accessed: January , 2018]

Sutton, R.S. and Barto, A.G. (1998) Reinforcement learning: An introduction. MIT press.

Takim, R., Zulkifli, M. H. and Nawawi, A. H. (2016) Integration of Automated Safety Rule Checking (asrc) System for Safety Planning BIM-based Projects in Malaysia. Procedia - Social and Behavioral Sciences, Vol. 222, pp. 103-110. DOI: https://doi.org/10.1016/j.sbspro.2016.05.195

Underwood, J. and Isikdag, U. (2011) Emerging Technologies for BIM 2.0. Construction Innovation, Vol. $11, \quad$ No. $\quad 3, \quad$ pp. 252-258. DOI: https://doi.org/10.1108/14714171111148990

Vanlande R., Nicolle C. and Cruz C. (2008) IFC and Building Lifecycle Management. Automation in Construction, Vol. 18, No. 1, pp. 70-78. DOI: https://doi.org/10.1016/j.autcon.2008.05.001

Wang, J. (2014) Encyclopedia of Business Analytics and Optimization. Hershey, Pa.: Business Science Reference.

Wang, J. and Ruxton, T. (1997) Design for Safety, Professional Safety, Vol. 42, No. 1, pp. 2429.

Wetzel Eric, M., Lucas, J. and Thabet Walid, Y. (2017) The Utilization of an Asset Safety Identification Tool (ASIT) to Support Safety During Facilities Management. ASCE 
International Workshop on Computing in Civil Engineering. DOI: https://doi.org/10.1061/9780784480823.002

Wetzel, E. M. and Thabet, W. Y. (2015) The Use of a BIM-based Framework to Support Safe Facility Management Processes. Automation in Construction, Vol. 60, pp. 12-24. DOI: https://doi.org/10.1016/j.autcon.2015.09.004

Wetzel, E. M. and Thabet, W. Y. (2016) Utilizing Six Sigma to Develop Standard Attributes for a Safety for Facilities Management (SFFM) Framework. Safety Science, Vol. 89, pp. 355-368. DOI: https://doi.org/10.1016/j.ssci.2016.07.010

X. Wu, Y. Liu and I. Gorton, (2015) Exploring Performance Models of Hadoop Applications on Cloud Architecture, 11th International ACM SIGSOFT Conference on Quality of Software Architectures (QoSA), Montreal, QC, pp. 93-101.

Zhang, S., Sulankivi, K., Kiviniemi, M., Romo, I., Eastman, C. M. and Teizer, J. (2015) BIMbased Fall Hazard Identification and Prevention in Construction Safety Planning. Safety Science, Vol. 72, pp. 31-45. DOI: https://doi.org/10.1016/j.ssci.2014.08.001

Zhang, S., Teizer, J., Lee, J.-K., Eastman, C. M. and Venugopal, M. (2013) Building Information Modeling (BIM) and Safety: Automatic Safety Checking of Construction Models and Schedules. Automation in Construction, Vol. 29, pp. 183-195. DOI: https://doi.org/10.1016/j.autcon.2012.05.006

Zou, Y., Kiviniemi, A. and Jones, S. W. (2017) A Review of Risk Management Through BIM and BIM-related Technologies. Safety Science, Vol. 97, pp. 88-98. DOI: https://doi.org/10.1016/j.ssci.2015.12.027 
Figure 1 - Inception of Digital Sensory Evaluation when Engineering out Risks with Continuous Monitoring of Confined Spaces

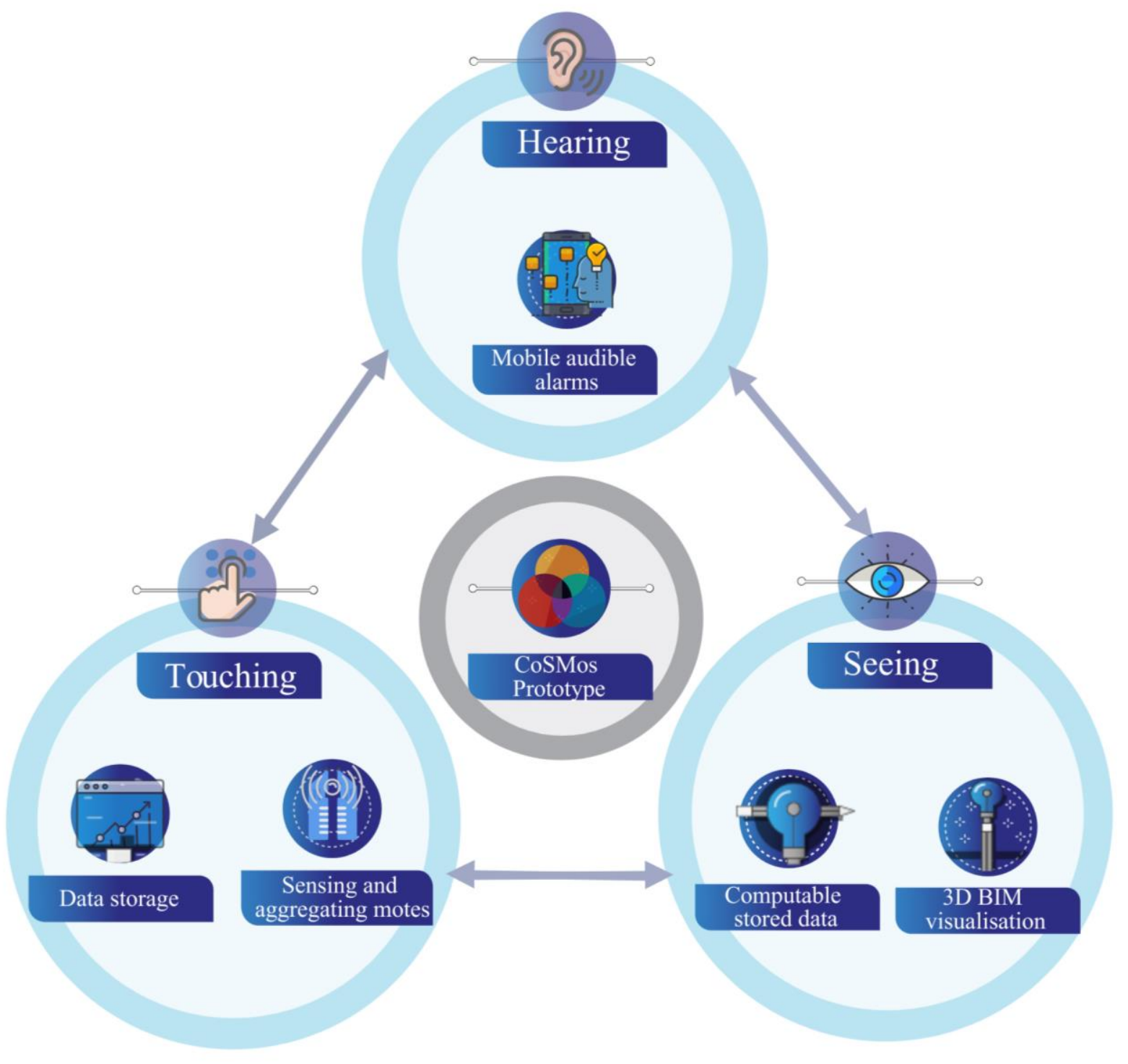


Figure 2 - Confined Spaces of a Facility Visualised in BIM

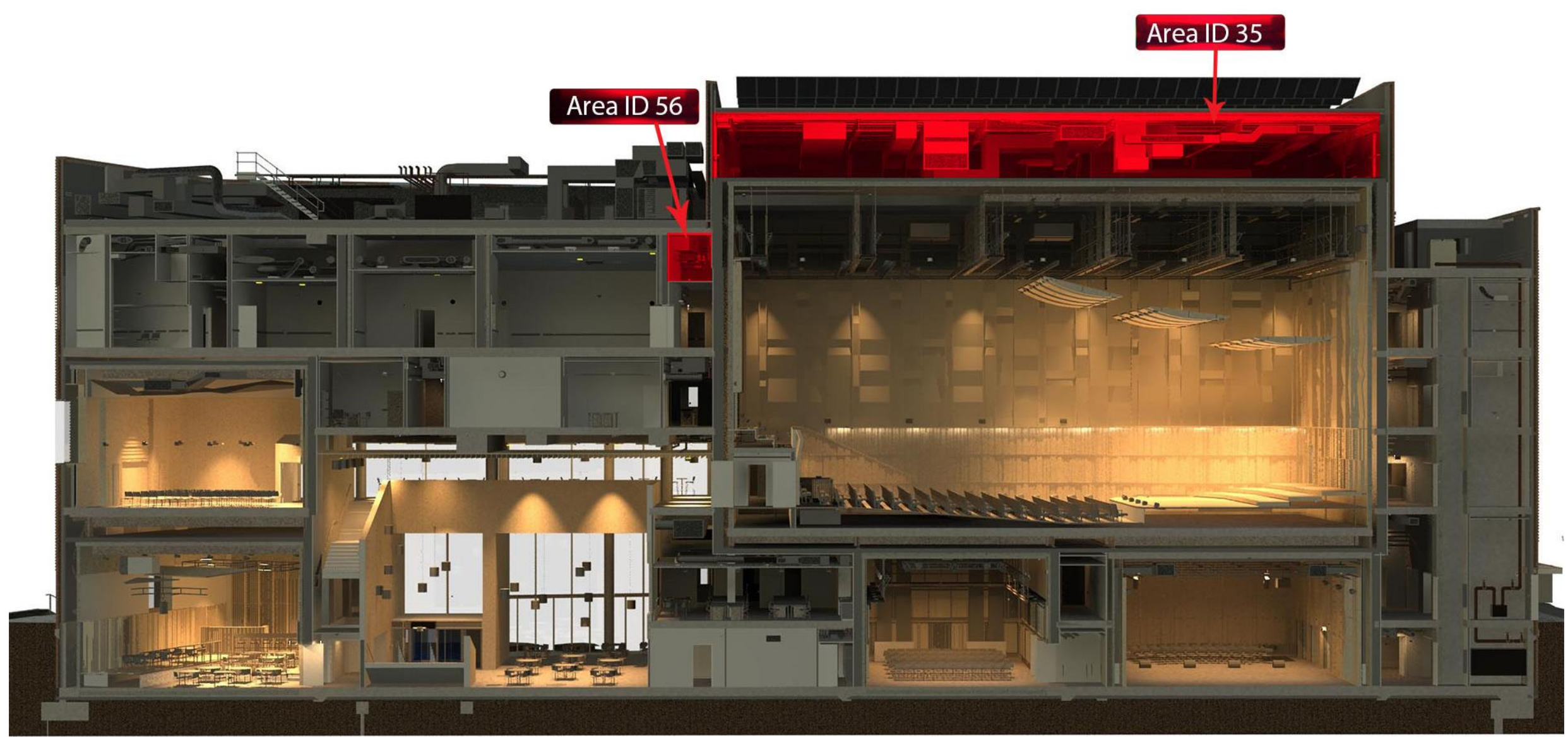


Figure 3 - API Development of CoSMoS for Monitoring of H\&S Hazards in Confined Spaces
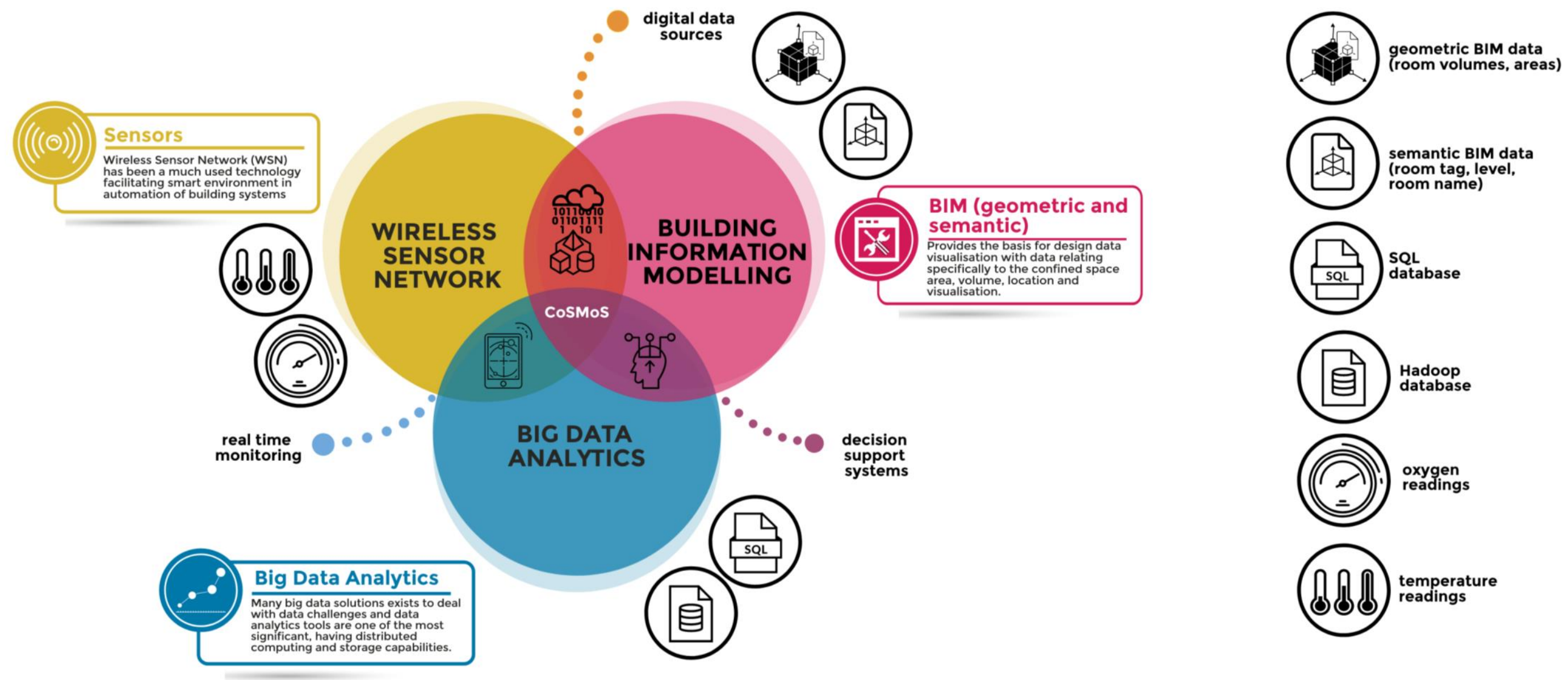
Figure 4 - CoSMoS Sensor Analytics of Daily Oxygen and Temperature Readings
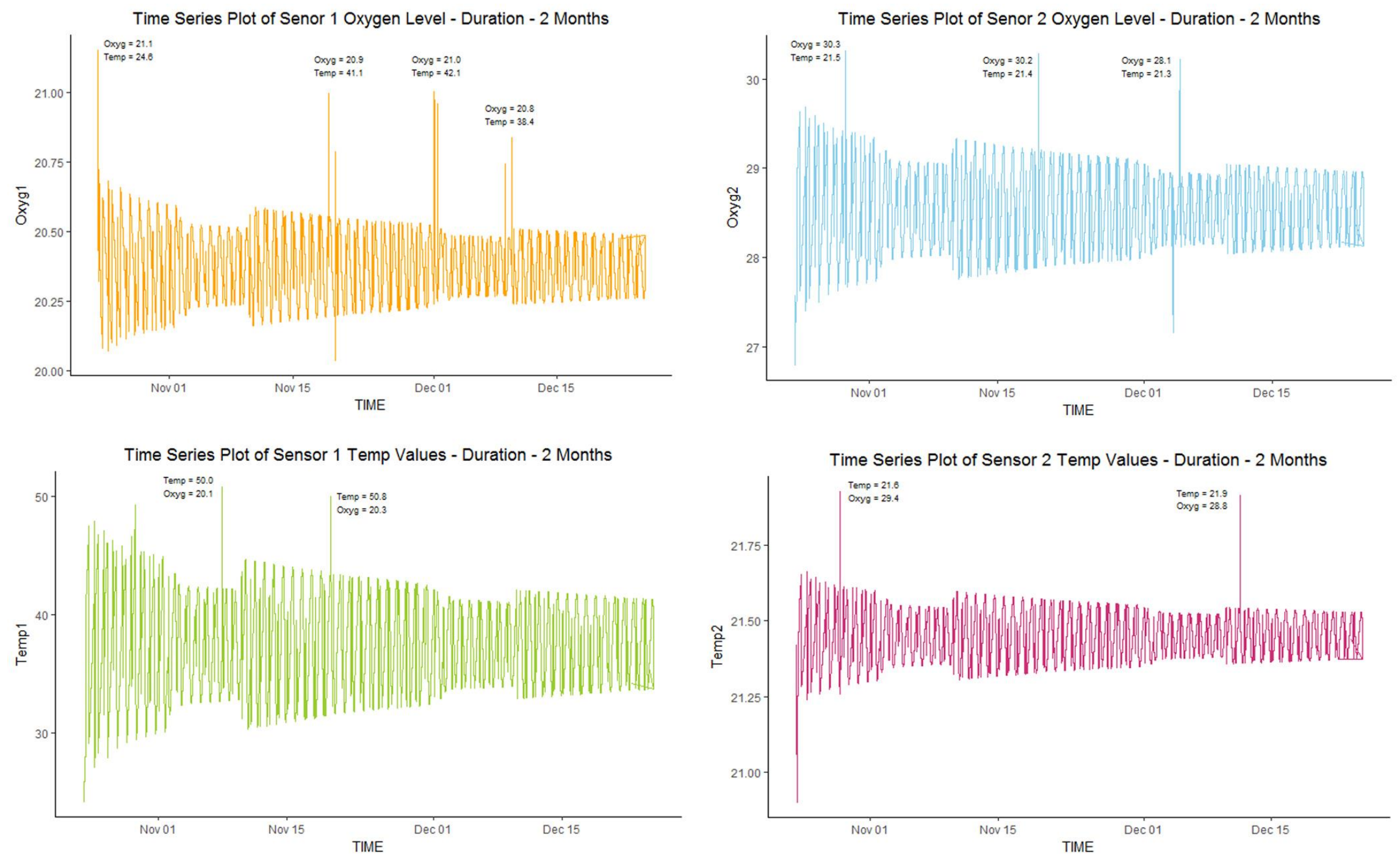
Figure 5 - CoSMoS Sensor Analytics of Monthly Oxygen and Temperature Readings
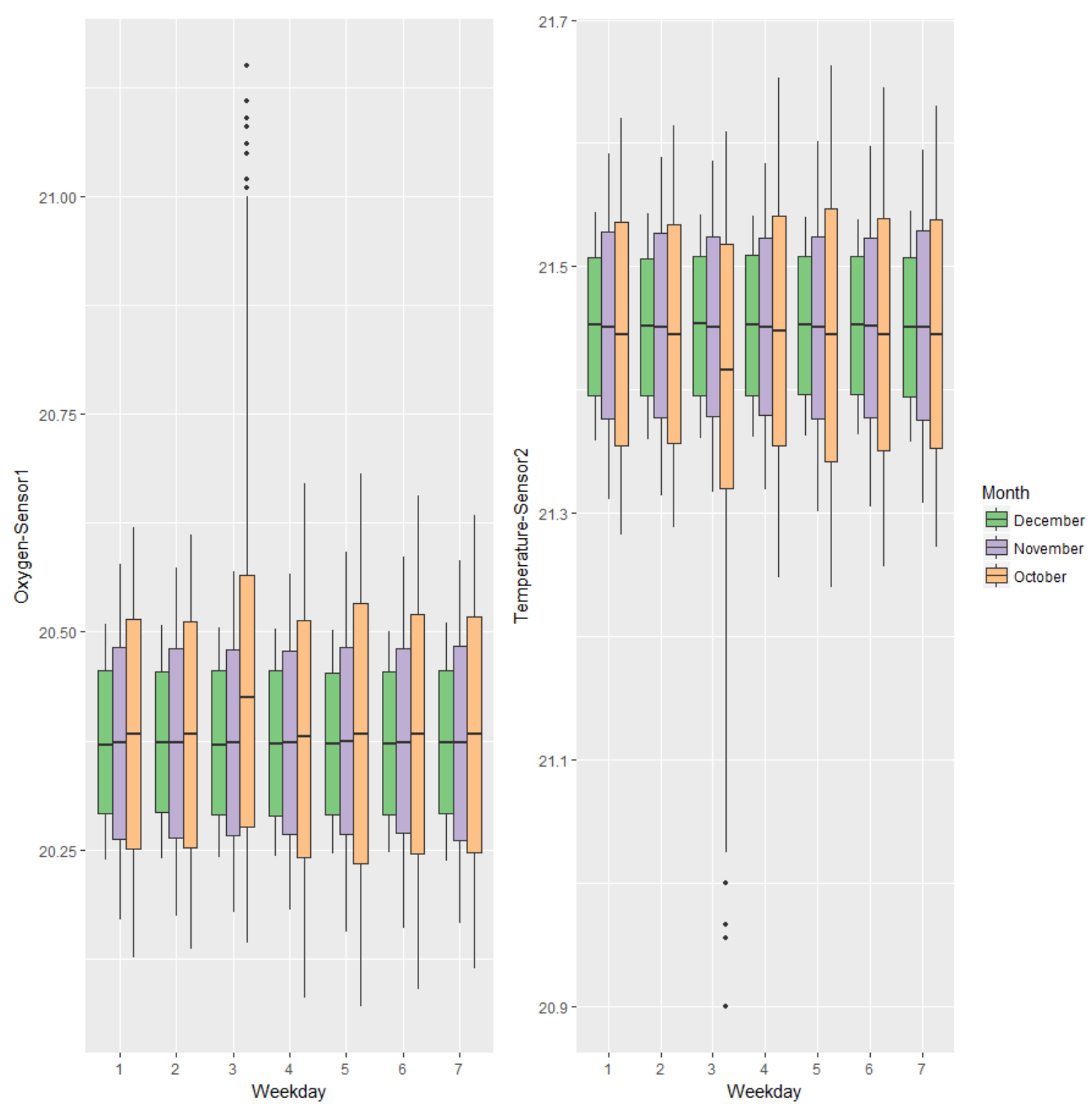